\title{
Analysis of a terminal Xp22.3 deletion in a patient with six monogenic disorders: implications for the mapping of $\mathrm{X}$ linked ocular albinism
}

\author{
Alfons Meindl, Detlev Hosenfeld, Wolfgang Brückl, Simone Schuffenhauer, \\ Jutta Jenderny, Arno Bacskulin, Hans-Conrad Oppermann, O Swensson, \\ Pierre Bouloux, Thomas Meitinger
}

\begin{abstract}
The molecular characterisation of chromosomal aberrations in Xp22.3 has established the map position of several genes with mutations resulting in diverse phenotypes such as short stature (SS), chondrodysplasia punctata (CDPX), mental retardation (MRX), ichthyosis (XLI), and Kallmann syndrome (KAL). We describe the clinical symptoms of a patient with a complex syndrome compatible with all these conditions plus ocular albinism (OA1). He has a terminal $\mathrm{Xp}$ deletion of at least $10 \mathrm{Mb}$ of DNA. Both the mother and sister of the patient are carriers of the deletion and show a number of traits seen in Turner's syndrome. The diagnosis of ocular albinism was confirmed in the patient and his mother, who shows iris translucency, patches and streaks of hypopigmentation in the fundus, and macromelanosomes in epidermal melanocytes. By comparative deletion mapping we can define a deletion interval, which locates the OA1 gene proximal to DXS143 and distal to DXS85, with the breakpoints providing valuable starting points for cloning strategies. (f Med Genet 1993;30:838-42)
\end{abstract}

Interstitial and terminal deletions in Xp22.3 are associated with monogenic disorders such as short stature, chondrodysplasia punctata, mental retardation, $\mathrm{X}$ linked ichthyosis, and Kallmann syndrome, which can occur singly or together. Male patients with deletions in $\mathrm{Xp22.3}$ are nullisomic for this region and therefore they show various phenotypes according to the length of the deletion involved. ${ }^{1}$ While genes associated with $\mathrm{X}$ linked ichthyosis ${ }^{23}$ and Kallmann syndrome ${ }^{45}$ have been cloned, those for chondrodysplasia and mental retardation have not. Patients manifesting contiguous gene syndromes, including ocular albinism (OA1), have been published, but these reports lack either hard clinical evidence ${ }^{6}$ or clear molecular data. ${ }^{7}$

The physical map of Xp22.3 comprises more than nine million base pairs $(\mathrm{Mb}){ }^{8}$ including the whole of the pseudoautosomal region. A large number of deletions and translocations have been assembled in order to narrow cloning intervals for genes in this chromosomal region. ${ }^{39-11}$ However, the gene posi- tion for ocular albinism remains unresolved. ${ }^{12}$ Two alternative orders have been suggested: the putative OA1 locus has been placed distal ${ }^{13}$ and proximal ${ }^{14}{ }^{15}$ to the locus DXS143 by linkage analysis.

Here we describe a patient with a large Xp22.3 deletion who has ocular albinism in addition to short stature, chondrodysplasia punctata, mental retardation, ichthyosis, and Kallmann syndrome. Clinical investigation of the family was followed by cytogenetic analysis and comparative deletion mapping.

\section{Methods}

PATIENTS

A detailed clinical description of the patient (W1) with symptoms of mental retardation, ichthyosis, and Kallmann syndrome was reported by Pike et al. ${ }^{16} \mathrm{~A}$ recent ophthalmological examination has shown no signs of ocular albinism (normal vision, normal fundus, no nystagmus). Growth assessment was performed according to tables published in the Netherlands. ${ }^{17}$

\section{CYTOGENETIC ANALYSIS}

High resolution chromosomal analysis of peripheral lymphocytes of the patient BK and his mother were performed according to Yunis ${ }^{18}$ using amethopterin as the synchronising agent and Giemsa-Trypsin banding. The inactivation pattern of the $\mathrm{X}$ chromosome in the mother was investigated using bromodeoxyuridine as the synchronising agent and fluorochrome-photolysis-Giemsa staining. ${ }^{19}$

\section{DNA ANALYSIS}

DNA extraction, Southern blotting, and pulsed field gel electrophoresis (PFGE) were carried out as described previously. ${ }^{20}$ DNA probes used for hybridisation are summarised in the table.

\section{Case reports}

The patient investigated in this study (BK) is 9 years old and shows signs of a complex syndrome involving the eyes, brain, skeletal system, and skin. He was born after two miscarriages as the second child of unrelated parents. $\mathrm{He}$ has two healthy brothers and a sister. 


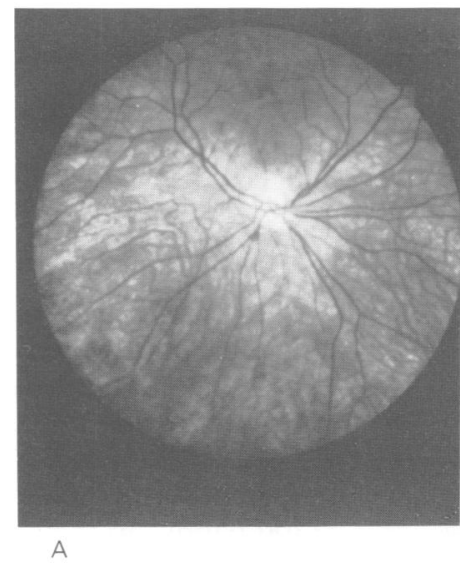

Figure 1 Demonstration of the carrier status for ocular albinism in the mother of patient BK. (A) Fundus of the patient's mother showing typical 'mud splattered' appearance. (B) Fluorescein angiography of choroidal vessels showing the characteristic hairpin phenomenon. (C) Electron microscopic picture taken from a skin biopsy of the patient's mother showing stratum papillare of the dermis (D) and stratum basale of the epidermis (E).A macromelanocyte $(M)$ with a macromelanosome (big arrow) is located between keratinocytes and basal membrane (arrow heads).

Placental insufficiency had been assumed in the 37 th week of gestation after measuring low levels of oestradiol. Delivery was spontaneous in the 40th week of pregnancy. Hypertriglyceridaemia and a large heart were noted soon after birth.

Growth parameters measured were far below normal levels. Weight at birth was $2400 \mathrm{~g}$ (mean $-4 \mathrm{SD}$ ), length $40 \mathrm{~cm}$ (mean $-5 \mathrm{SD}$ ), and head circumference $32 \mathrm{~cm}$ (mean $-3 \mathrm{SD}$ ). The patient's height at the age of $8 \frac{1}{2}$ years was $102 \mathrm{~cm}$ (mean $-5 \mathrm{SD}$ ), the upper/lower ratio

Probes and hybridisation results.

\begin{tabular}{|c|c|c|c|c|}
\hline Probe & Reference & Locus & BK & W1 \\
\hline $\begin{array}{l}\text { ANT-3 } \\
\text { p19B } \\
\text { P39 } \\
\text { M1A } \\
\text { pTAK10 } \\
\text { STB14 } \\
\text { GMGX9 } \\
\text { p23A } \\
\text { dic56 } \\
\text { p45 } \\
782 \\
71-7 A\end{array}$ & $\begin{array}{r}21 \\
22 \\
23 \\
24 \\
25 \\
3 \\
26 \\
4 \\
27 \\
22 \\
28\end{array}$ & $\begin{array}{l}\text { ANT-3 } \\
\text { MIC2 } \\
\text { DXS409 } \\
\text { DXS31 } \\
\text { DXS89 } \\
\text { STS } \\
\text { DXS237 } \\
\text { KAL-X } \\
\text { DXS143 } \\
\text { DXS410 } \\
\text { DXS85 }\end{array}$ & $\begin{array}{l}- \\
- \\
- \\
- \\
- \\
- \\
- \\
- \\
- \\
\overline{1200(\mathrm{M}) \mathrm{J}} \\
600(\mathrm{~N}) \mathrm{J} \\
900(\mathrm{~S})\end{array}$ & $\begin{array}{l}+ \\
+ \\
- \\
- \\
- \\
- \\
- \\
- \\
400(\mathrm{M}) \\
1000(\mathrm{M}) \\
500(\mathrm{~N}) \\
900(\mathrm{~S})\end{array}$ \\
\hline
\end{tabular}

+ and - indicate presence or absence of hybridisation with DNA samples of patients BK and W1. For the pseudoautosomal locus ANT $-3,+$ and - indicate double and single dosage. BK was deleted for X specific MIC2 fragments observed in the mother; W1 showed both a Y specific and an X specific MIC2 fragment. Detected PFGE fragments are given in $\mathrm{kb}: \mathrm{N}=\operatorname{Not} \mathrm{I}, \mathrm{M}=M$ lu $\mathrm{I}$ $S=S s t I I$ : fragments found in patient $W_{1}$ correspond to fragments found in 10 controls. $\mathrm{J}=$ junction fragment; see fig 5 .

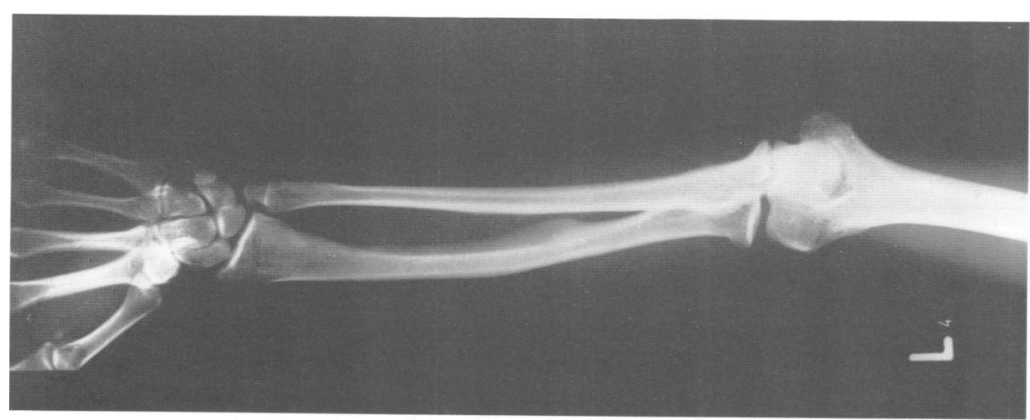

Figure $2 X$ ray of the left lower arm of the patient's mother. Madelung deformity is obvious with bowing of the radius, sloping of the distal end, and hypoplastic distal ulna. was 1.4 (normal 1.01), and the head circumference was $51.5 \mathrm{~cm}$ (mean $-1.5 \mathrm{SD}$ ).

Dysmorphic features suggested the diagnosis of chondrodysplasia punctata which was confirmed soon after birth by radiographs showing multiple stippled calcifications of the epiphyses, predominantly in the paravertebral region and the neighbourhood of the carpal and tarsal bones. Metacarpophalangeal pattern profile analysis (at the age of 5) showed shortening of metacarpals 1 to 4 and pronounced brachyteledactyly. Ulnar deviation of the wrist was noted which was caused by hypoplasia of the distal ulna. Dysmorphic features of the face included a broad, flat nose with anteverted nares and a small lateral groove, short columella, pouting upper lip, and hypoplasia of the maxilla. Lateral $x$ ray of the skull at the age of 15 months confirmed the maxillonasal dysplasia and absence of the anterior nasal spine, the 'Binder phenotype'. ${ }^{3031}$ Psychomotor retardation became evident at the age of 3 months. He started to stand at $3 \frac{1}{2}$ years and to walk independently after his sixth birthday. He did not learn to speak. He recognises persons familiar to him and he shows pleasure at their touch.

Ichthyosis was diagnosed at the age of 5 and hyperkeratosis was fully developed at the age of 7 . At the age of 8 years, Kallmann syndrome was assumed because of microgenitalia and cryptorchidism in addition to mirror movements. His sense of smell could not be assessed.

Ocular albinism was diagnosed after an ophthalmological investigation under anaesthesia at the age of 7 months. A poorly pigmented fundus, aplasia of the macula and choroid, and a horizontal nystagmus were noted. Iris translucency, 'mud splattered fundus', and a reduction of pigmentary epithelium confirmed the carrier status of his mother (fig 1A,B). This diagnosis was confirmed by showing the presence of macromelanosomes in an electron microscopic study of a skin punch biopsy (fig 1C). 

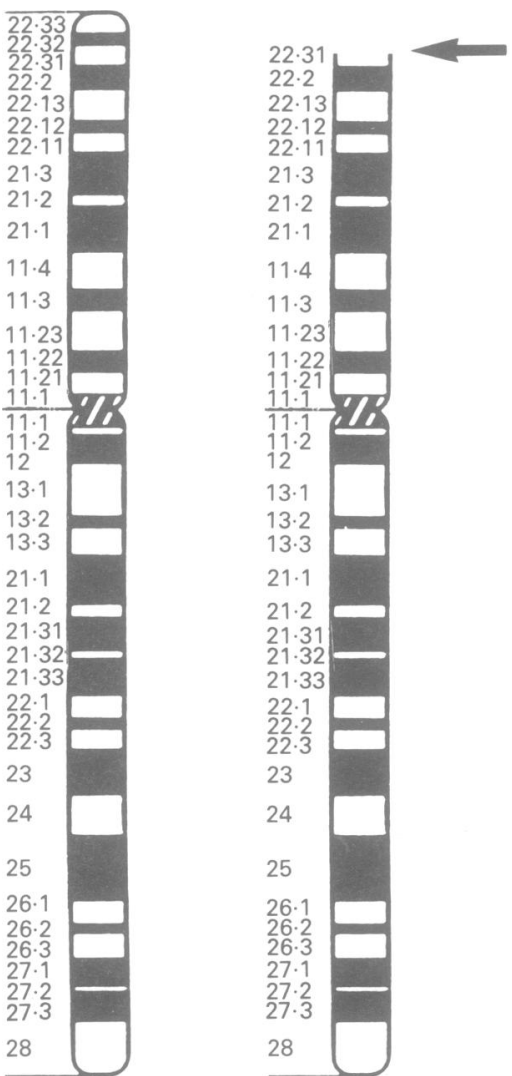

Figure 3 High resolution $G$ banding of obligate female carrier showing terminal $X$ p22.3 deletion. Idiograms of the normal and deleted $X$ chromosomes are shown on the left, high resolution banding of the $X$ chromosomes (about 700 bands) on the right. The terminal Xp22.3 deletion is indicated by an arrow.

Other symptoms indicating the carrier status of the mother and sister were noted. Moderate psychomotor retardation was found in the 5 year old sister. She has a short neck, but no signs of a pterygium, and the nipple distance is increased. Hypoplasia of the distal ulna is present, although to a lesser degree than in her brother. The mother has pigmented naevi, a low posterior hair line, and a Madelung deformity (fig 2 ). Other $x$ ray abnormalities include the metacarpal sign and diminished carpal size (mean - 4 SD), but the carpal angle was normal. ${ }^{32}$ A remarkably similar dermatoglyphic pattern to that in Turner's syndrome patients was found in the patient, his mother, and his sister (total ridge count raised, high frequency of whorls, hypothenar pattern, distal carpal triradii). Both the mother and sister have short stature. The mother's height is $150 \mathrm{~cm}$ (mean $-2.6 \mathrm{SD}$ ), the target range is
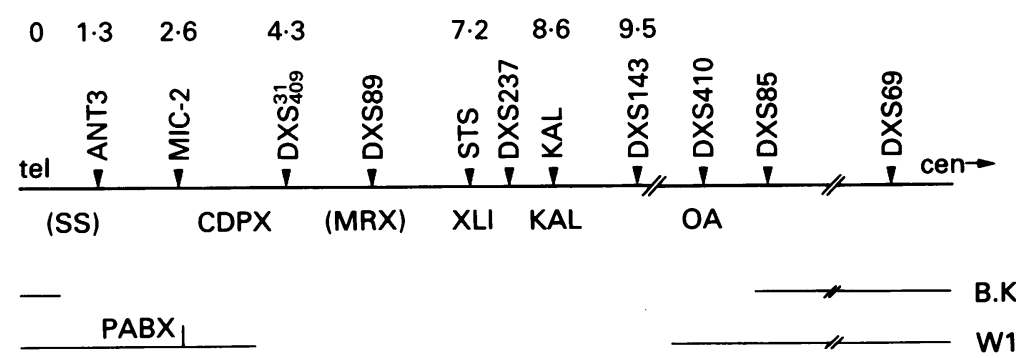
Figure 4 Deletion map of patients $B K$ and $W 1$. The extent of the deletions according
to the probes tested (table) are indicated. Distances from the telomere are given in $M b$ according to Petit et al. ${ }^{8}$ The position of the pseudoautosomal boundary on the $X$ chromosome is shown (PABX).
$165 \pm 4.2 \mathrm{~cm}$, and the head circumference is $51.5 \mathrm{~cm}$ (mean $-2 \mathrm{SD}$ ). The height of the sister at the age of $4 \frac{1}{2}$ years was $94 \mathrm{~cm}$ (mean $-2 \mathrm{SD})$ and the head circumference was $48.5 \mathrm{~cm}$ (mean $-2 \mathrm{SD}$ ).

\section{Results of cytogenetic and DNA investigations}

High resolution chromosomal analysis showed the karyotype $46, \mathrm{Y}, \operatorname{del}(\mathrm{X})(\mathrm{p} 22.3)$ in the patient ( 700 bands, 30 metaphases) and the karyotype $46, \mathrm{X}, \operatorname{del}(\mathrm{X})(\mathrm{p} 22.3)$ in his mother (700 bands, 50 metaphases) (fig 3 ).

Genomic DNA of patients BK and W1 was characterised by Southern and PFGE analysis. Twelve DNA probes were used from Xp22.3 ranging from ANT3 in the pseudoautosomal region to p71-7A (DXS69), which maps more than $10 \mathrm{Mb}$ away from the telomere ( $\mathrm{M} \mathrm{Wap}$ penaar, personal communication). In an attempt to identify junction fragments at the proximal breakpoints, PFGE experiments were performed using the following probes: P45 (DXS410), 782 (DXS85), and p71-7A (DXS69). The results of these hybridisation experiments are summarised in the table.

The large deletion in patient BK corresponded to absent hybridisation signals with all probes used except 782 (DXS85) and p71-7A (DXS69). In contrast to patient W1, the probe P45 (DXS410) was deleted in BK (fig 4). Furthermore, altered $M l u \mathrm{I}$ and NotI fragments were detected with probe 782 (fig 5), which were not found in 10 control females and in patient $W 1$. Unaltered fragments were identified in both patients with probe p71-7A, indicating that it maps proximal to probe 782 . These data suggest that the critical interval for OA1 is located between DXS143 and DXS85, segregating with the locus DXS410.

\section{Discussion}

This patient, with a contiguous gene syndrome, shows a deletion of more than $10 \mathrm{Mb}$. Cytogenetically, the deletion comprises most of band Xp22.3. On DNA analysis, the most distal probe tested and deleted is ANT3, which maps $1.3 \mathrm{Mb}$ away from the telomere in the pseudoautosomal region. ${ }^{21}$ Nine other Xp22.3 probes analysed are deleted including P45 (DXS410) which maps more than $10 \mathrm{Mb}$ away from the telomere ( $M$ Wappenaar, personal communication). Ten genes are assigned to the deleted region. They include four genes which so far have not been associated with human disease: a gene for an adenine nucleotide translocase (ANT3), a gene for a colony stimulating factor receptor (CSF), ${ }^{33}$ a gene for the leucocyte antigen $\mathrm{MIC} 2,{ }^{22}$ and the gene GS1. ${ }^{34} \mathrm{Six}$ other genes include those with mutations leading to short stature, chondrodysplasia punctata, mental retardation, ichthyosis, Kallmann syndrome, and ocular albinism. Patient BK shows symptoms of all these disorders. Additional phenotypes could be obscured by this complex clinical picture. The so far unexplained hypertriglyceridaemia, 


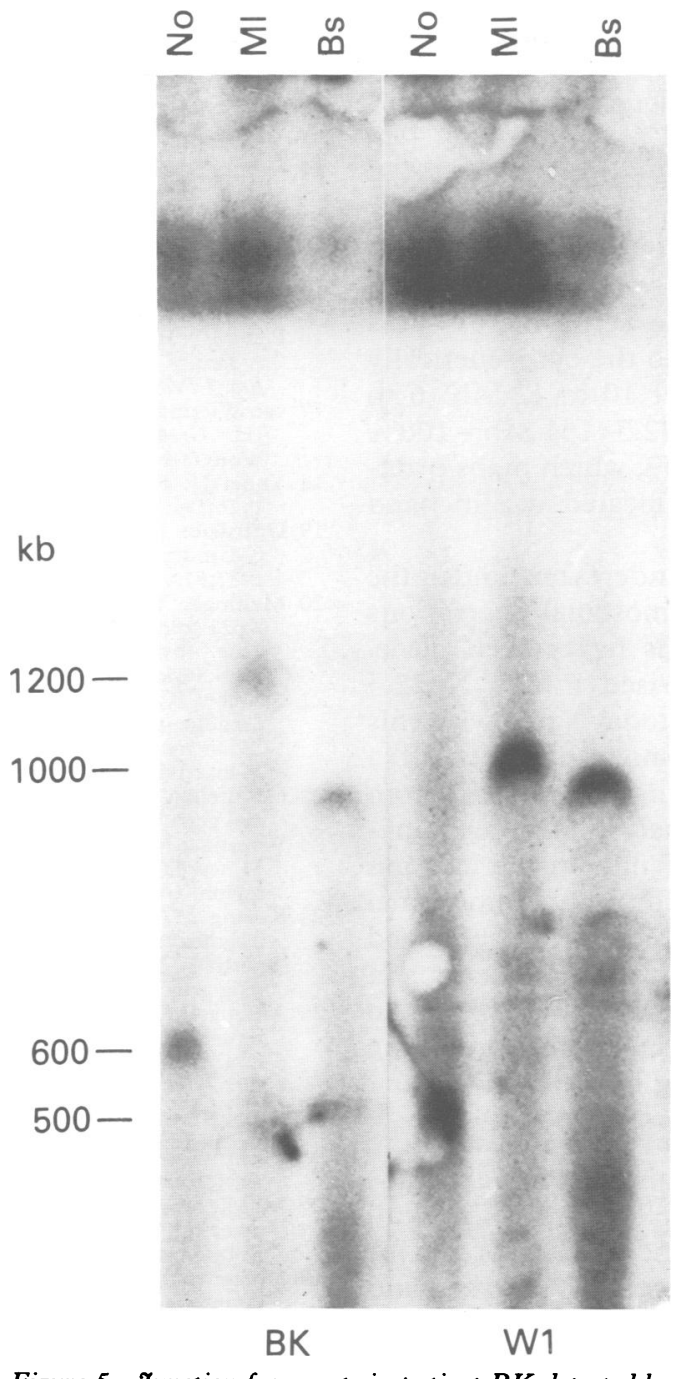

Figure 5 function fragments in patient $B K$ detected by the probe 784 (DXS85). High molecular DNA from patients $B K$ and $W 1$ was digested with the rare cutters NotI (No), MluI (MI), and BssHI (Bs), respectively, and blotted after PFGE onto a nylon membrane. The filter was hybridised with probe 784 and washed under stringent conditions $\left(60^{\circ} \mathrm{C}, 0 \cdot 1 \times S S C\right)$. Exposure time was four days. Fragment lengths $(k b)$ are indicated.

for example, could suggest a gene affecting lipid metabolism.

The presence of a growth gene(s) has been postulated after analyses of karyotypes from $X$ chromosome rearrangements at the tip of $\mathrm{Xp} .{ }^{35}$ The critical region for the putative growth gene(s) comprises the pseudoautosomal region between the telomere and locus DXYS17 which maps about $2 \mathrm{Mb}$ proximal to the telomere. ${ }^{11}$ The deletion described includes ANT3, which maps to the critical region. The height of patient BK remained far below the 3rd centile (mean - 5 SD), much shorter than in patients with chondrodysplasia punctata. ${ }^{30}$ Moderate short stature of female carriers with $\mathrm{Xp} 22.3$ deletions has been reported by Curry et $a l^{36}$ and Ballabio et al. ${ }^{9}$ Both carrier women investigated had short stature, as well as several symptoms typically seen in Turner's syndrome. These include a low posterior hair line and pigmented naevi in the mother, a short neck and hypoplasia of the distal ulna in the sister, as well as abnormal palmar dermatoglyphs in both and Madelung deformity in the mother. All these symptoms should result from unbalanced gene expression within the deleted region where several genes have been shown to escape $\mathrm{X}$ inactivation. ${ }^{1}$

The typical features of chondrodysplasia punctata are present in patient BK. They include alterations of epiphyseal bones, brachytelephalangy, and the peculiar dysmorphic features, a manifestation mimicked by warfarin embryopathy. ${ }^{3037}$ No signs of chondrodysplasia punctata were described in patient W $1 .^{16}$ This is in concordance with positive hybridisation results for MIC2 (table) and for a probe which maps distal to MIC2.

Of all the symptoms in this case, mental retardation is the most general. The number of missing transcripts in the deletion described could contribute to reduced cerebral function, a hypothesis which gains support from the observation that the extent of mental retardation seems to correspond to the length of the terminal deletions described. Patient $\mathrm{BK}$ is severely mentally retarded but a milder expression has been described in patient W1 (table) who has a much smaller deletion. ${ }^{16}$

The diagnosis of ichthyosis and Kallmann syndrome is consistent with the absent hybridisation signals for both the STS and the KAL-X cDNA. Although the endocrinological status has not been assessed, the mirror movements recorded are pathognomonic of this condition (our observation and B Heye, personal communication).

Two linkage analyses, published recently, map the OA gene proximal to KAL-X.1538 Single recombinants analysed in a large Newfoundland kindred define a critical interval for the OAl gene between the loci DXS143 and DXS85. ${ }^{15}$ For deletion mapping of the OA gene, special emphasis has been placed on the ocular condition in patient BK and his family. Ocular symptoms observed in the patient, his mother, and his sister are consistent with the diagnosis of $\mathrm{X}$ linked ocular albinism. Nettleship-Falls type of ocular albinism is characterised by poor visual acuity, nystagmus, macular hypoplasia, and hypopigmentation of the retina as well as the iris. ${ }^{3940}$ Carrier females show a 'mud splattered' appearance of the fundus with hyperpigmented streaks and most of them have iris translucency and macromelanosomes. ${ }^{41}$ Both the aberrant fundus appearance and macromelanosomes were found in the patient's mother who carried the Xp22.3 deletion on one $\mathrm{X}$ chromosome.

In contrast, no symptoms of ocular albinism were observed in patient W1. This patient presents mental retardation, ichthyosis, and Kallmann syndrome because of a deletion involving the loci distal as well as proximal to the STS and KAL-X genes (table). Both patients are deleted for DXS143 which, according to the physical map of this region, maps proximal to the KAL-X gene. The locus DXS410 is deleted in BK, but not in W1. The junction fragments seen with probe 782 (DXS85) in BK indicate a breakpoint close to this probe. Probes more proximal give rise to unaltered fragments in both patients. The two proximal breakpoints of patients $\mathrm{BK}$ and W1 therefore define a deletion interval which 
should contain the OAl gene (fig 4). The minimum distance of this interval measures $400 \mathrm{~kb}$ because of the length of the MluI fragment detected in W1 with probe P45 (DXS410). The maximum interval is determined by the distance between the loci DXS143 and DXS85. This distance is unlikely to be larger than 1 to $2 \mathrm{Mb}$ : DXS143 has been mapped $9.5 \mathrm{Mb}$ from the centromere. ${ }^{8}$ This distance is already close to the cytogenetically estimated length of about 10 to $12 \mathrm{Mb}$ (6 to $7 \%)$ for the whole of Xp22.3 (164 Mb $=100 \%$ for the whole X) ${ }^{42}$ DXS69, which maps proximal to DXS85, is also located within band $\mathrm{Xp} 22.31 .^{43}$

Deletion mapping is undertaken under the assumption that no chromosomal aberrations other than plain deletions have taken place. Most deletions characterised in the Xp22.3 region by DNA markers today agree with this assumption. ${ }^{1}$ There are no indications of a complex rearrangement in patient BK from cytogenetic and DNA analysis. One explanation for the discrepant results on the location of the OAl gene is a complex chromosomal rearrangement in one of the patients published recently. ${ }^{7}$ Analysis of terminal $\mathrm{Xp}$ deletions in this study places the OA1 gene proximal to DXS143 and distal to DXS85, thus providing starting points for cloning of the OA1 gene.

We are grateful to $M$ Kautza for investigating the family of BK. We thank H Fischer-Brandies for cephalometric evaluation of the skull radiographs, $\mathrm{H}$ Achatz and $\mathrm{H}$ Hellebrand for expert technical assistance, and J Murken and W Grote for their continuous support. Probes were kindly provided by $M$ Wapenaar, A Ballabio, and $G$ Rappold. This work was supported by the Deutsche Forschungsgemeinschaft (TM, AM)

1 Ballabio A, Andria G. Deletions and translocations involving the distal short arm of the human $\mathrm{X}$ chromosome: review and hypotheses. Hum Mol Genet 1992;1:221-7.

2 Ballabio A, Sebastio G, Carozzo R, et al. Deletions of the steroid sulphatase in classical X-linked ichthyosis and in $\mathrm{X}$-linked ichthyosis associated with Kallmann's syndrome. Hum Genet 1987;77:338-41.

3 Yen PH, Allen E, Marsh B, et al. Cloning and expression of steroid sulfatase CDNA and the frequent occurrence of deletions in STS deficiency: implication of X-Y interchange. Cell 1987;49:443-54.

4 Franco B, Guioli S, Pragliola A, et al. A gene deleted in Kallmann's syndrome shares homology with neural cell adhesion and axonal path-finding molecules. Nature 1992;353:529-36.

5 Legouis R, Hardelin JP, Levilliers J, et al. The candidate gene for the C-linked Kallmann syndrome encodes a protein related to adhesion molecules. Cell 1992;67:423 35 .

6 Sunohara N, Sakuragawa N, Satoyoshi E, Tanae A, Shapiro LJ. A new syndrome of anosmia, ichthyosis, hypogonadism and various neurological manifestations with gonadism and various neurological manifestations with deficiency of steroid sulfa

7 Schnur RE, Trask BJ, van den Engh G, et al. An Xp22 microdeletion associated with ocular albinism and ich thyosis: approximation of breakpoints and estimation of thyosis: approximation of breakpoints and estimation of deletion size by using cloned DNA probes

8 Petit C, Levilliers J, Weissenbach J. Long range restriction map of the terminal part of the short arm of the human $\mathrm{X}$ chromosome. Proc Natl Acad Sci USA 1990;87:3680-4.

9 Ballabio A, Parenti G, Carrozzo R, et al. Contiguous gen syndromes due to deletions in the distal short arm of the human $\mathrm{X}$ chromosome. Proc Natl Acad Sci USA 1989;86:10001-5.

10 Petit C, Melki J, Levilliers J, Serville F, Weissenbach J, Maroteaux P. An interstitial deletion in Xp22.3 in family with X-linked chondrodysplasia punctata and short stature. Hum Genet 1990;85:247-50

11 Ogata T, Petit C, Rappold G. Matsuo N, Matsumoto T, Goodfellow P. Chromosomal localisation of a pseudoautosomal growth gene(s). 7 Med Genet 1992;29:624-8.
12 Charles SJ, Moore AT, Yates JRW. Genetic mapping of X linked ocular albinism: linkage analysis in British families f Med Genet 1992;29:552-4.

13 Bergen AAB, Schuurman EJM, VanDosch L, et al. Multipoint linkage analysis in X-linked ocular albinism of the Nettleship-Falls type (OA1). Hum Genet 1991;88:162-6.

14 Schnur RE, Nussbaum RL, Anson-Cartwright L, McDowell C, Worton R, Musarella MA. Linkage analysis in Xlinked ocular albinism. Genomics 1991;9:605-13.

15 Charles SJ, Green JS, Moore AT, Barton DE, Yates JRW. Genetic mapping of X-linked ocular albinism: linkage analysis in a large Newfoundland kindred. Genomics analysis in a large

16 Pike MG, Hammerton M, Edge J, Atherton DJ, Grant DB. A family with $\mathrm{X}$-linked ichthyosis and hypogonadism. Eur $\mathcal{F}$ Pediatr 1989;148:442-4.

17 van Wieringen JC, Wafelbakker F, Verbragge HP, de Haas JH. Growth diagrams 1965 Netherlands. Groningen: Wolters-Noordhoff, 1971 .

18 Yunis JJ. High resolution human chromosomes. Science 1976;191:1268-70.

19 Dutrillaux B, Viegas-Pequignot E. High resolution R- and G-banding on the same preparation. Hum Gene 1981;57:93-5.

20 Meitinger T, Boyd Y, Anand R, Craig IW. Mapping of $\mathrm{Xp21}$ translocation breakpoints in and around the $\mathrm{DMD}$ gene by pulsed field electrophoresis. Genomics 1988;3:315-22.

21 Schiebel K, Weiss B, Wöhrle D, Rappold G. A human pseudoautosomal gene, ADP/ATP translocase, escapes pseudoautosomal gene, ADP/ATP translocase, escapes X-inactivation whereas a homologue on X

22 Goodfellow P, Darling SM, Thomas NS. A pseudoautosomal gene in man. Science 1986;234:740-3.

23 Wapenaar M, Petit C, Basler E, et al. Physical mapping of 14 new DNA markers isolated from the human distal $\mathrm{Xp}$ region. Genomics 1992;13:167-75.

24 Koenig M, Camerino G, Heilig R, Mandel JL. A DNA fragment from the human $\mathrm{X}$ chromosome which detects a partially homologous sequence on the $\mathrm{Y}$ chromosome long arm. Nucleic Acids Res 1984;12:4079-109.

25 Ahrens P, Albertsen H, Rijs-Vestergard SR, Bolund L, Kruse TA. Anonymous X-chromosomal probes revealing DNA polymorphisms one of which is a deletion of more than 3.0 kb. Cytogenet Cell Genet 1985;40:567.

26 Gillard EF, Affara NA, Yates JRW, et al. Deletion of a DNA sequence in eight of nine families with $\mathrm{X}$-linked ichthyosis (steroid sulfatase deficiency) Nucleic Acids Res 1987;15:3977-85.

27 Middlesworth W, Bertelson C, Kunkel LM. An RFLP detecting single copy $\mathrm{X}$ chromosome fragment, dic 56 detecting single copy X chromosome fragment, dic
from Xp22-Xpter. Nucleic Acids Res 1985;13:5723.

28 Hofker MH, Wapenaar MC, Goor N, Bakker E, van Ommen GJB, Pearson PL. Isolation of probes detecting restriction fragment polymorphism from $\mathrm{X}$ chromosome specific libraries: potential use for diagnosis of Duchenne muscular dystrophy. Hum Genet 1985;70:148-56.

29 Kunkel LM, LaLande M, Monaco AP, Flint A, Middlesworth W, Latt SA. Construction of a human X-chromosome-enriched phage library which facilitates analysis of specific loci. Gene 1985;33:251-8.

30 Maroteaux P. Brachtelephalangic chondrodysplasia punctata: a possible X-linked recessive form. Hum Genet 1989;82:167-70

31 Sheffield LJ, Halliday JL, Jensen F. Maxillonasal dysplasia (Binder's syndrome) and chondrodysplasia punctata. $\mathcal{f}$ Med Genet 1991;28:503-4.

32 Poznanski AK. The hand in radiological diagnosis. 2nd ed. Philadelphia: Saunders, 1984

33 Gough NM, Gearing DP, Nicola NA, et al. Localization of the human GM-CSF receptor gene to the X-Y psuedoautosomal region. Nature 1990;345:734-6.

34 Yen PH, Ellison J, Salido EC, Mohandas T, Shapiro L. Isolation of a new gene from the distal short arm of the human $\mathrm{X}$ chromosome that escapes $\mathrm{X}$-inactivation. Hum Mol Genet 1992;1:47-52.

35 Simpson JL. Gonadal dysgenesis and abnormalities of the human sex chromosomes: current status of phenotypekaryotype correlations. Birth Defects 1975;11:23-59.

36 Curry CJR, Magenis RE, Brown M, et al. Inherited chondrodysplasia punctata due to deletion of the terminal short arm of an $\mathrm{X}$ chromosome. $N$ Engl $f$ Med 1984;311:1010-15.

37 Hosenfeld D. Chondrodysplasia punctata in an adult recognized as vitamin $\mathrm{K}$ antagonist embryopathy. Clin Genet

38 Bergen $A A B$, Zijp $P$, Schuurmann JM, Bleeker-Wagemakers EM, Apkarian P, van Ommen GJB. Refinement makers EM, Apkarian P, van Ommen GJB. Refinement of the localization of the
Genomics 1993;16:272-3

39 Creel D, O'Donnell FE, Witcop CJ. Visual system anomalies in human ocular albinos. Science 1978;201:931-3.

40 O'Donnell D, Hambrick GW, Green WR, et al. X linked ocular albinism. An oculocutaneous macromelanosomal ocular albinism. An oculocutaneous macrom
disorder. Arch Ophthalmol 1976;94:1883-92.

41 Charles SJ, Moore AT, Grant JW, Yates JRW. Genetic counselling in X-linked ocular albinism. Eye 1992;6:75-9. $42 \mathrm{NIH} / \mathrm{CEPH}$ Collaborative Mapping Group. A comprehensive genetic linkage map of the human genome. Science 1992;258:67-86.

43 de Martinville B, Kunkel LM, Bruns G, et al. Localisation of DNA sequences in region $\mathrm{Xp} 21$ of the human $\mathrm{X}$ chromosome: search for molecular markers close to the Duchenne muscular dystrophy locus. Am $f$ Hum Genet $1985 ; 37: 235-49$. 